\title{
Efficiency of the teaching-industry linkage in the Australian vocational education and training
}

\author{
Carolyn-Thi Thanh Dung Tran ${ }^{1,2^{*}}$ (])
}

\author{
${ }^{*}$ Correspondence: \\ carolyn.tran@sydney.edu.au \\ ${ }^{1}$ NSW Public Policy Institute, \\ The University of Sydney, \\ Sydney, NSW 2006, Australia \\ Full list of author information \\ is available at the end of the \\ article
}

\begin{abstract}
The vocational education and training (VET) sector plays a crucial role in Australia's education system. Associated closely between the VET provision and industry, VET training quality is continually at the heart of debates in the process of implementing the Australian VET reform agenda. In response of key themes of this reform process, investigating the training efficiency of VET through the linked efficiency between teaching and industry responsiveness is imperative. The paper aims to address this objective by using the dynamic network data envelopment analysis in a balanced panel data for 2008-2012. This advanced model allows to assess simultaneously the efficiency of two nodes, teaching and industry responsiveness, and the overall dynamic training efficiency of VET based on fields of education in a network structure. We found that the overall training efficiency of VET is, on average, 0.835 while the mean divisional efficiencies of the teaching efficiency and industry responsiveness are 0.763 and 0.908 , respectively. Sensitivity analysis is conducted to examine dynamic changes of the efficiency of the teaching and industry linkage following various period weights. Policy implications are drawn for the Australian VET sector.
\end{abstract}

Keywords: Data envelopment analysis, Efficiency, Fields of education, Vocational education and training, Australia

\section{Introduction}

The vocational education and training (VET) sector plays a crucial role in a nation's education system and has been the theme of reform in many countries over the world (Chappell 2003). Like other advanced countries such as the United Kingdom, Canada, and New Zealand, enhancing national incomes of VET has been at the heart of Australia's reform agenda for many years (Chhetri et al. 2018). However, the Australian VET system still faces constant challenges such as education quality, productivity growth, shortages of capable staff and mismatch between the skills supplied and the specific industry needs (Blumenfeld and Malik 2017; Chhetri et al. 2014, 2018; Adamson and Darling-Hammond, 2015; Weller 2017). These challenges have been received much concern of scholars and researchers to review the Australian VET reform agenda for the 
purpose of seeking appropriate strategies in order to move the sector forward (Clayton and Harris 2018).

In Australia, numerous studies have been conducted to peruse operational and cost efficiency and productivity growth of higher education institutions such as Avkiran (2001), Abbott and Doucouliagos (2003), Carrington, Coelli and Rao (2005), Lee (2011), Worthington and Higgs (2011), Lee and Worthington (2016), Zhang and Worthington (2017), Carrington et al. (2018) and the like. These studies to some extent provided useful information to educational managers and policy makers in designing more appropriate policies and regulations to enhance university performance. However, empirical research on the performance of the Australian VET sector has been quite limited. To our knowledge, very few studies focused on the analysis of efficiency and performance of technical and further education (TAFE) institutes in Australia. For example, Abbott and Doucouliagos (2002) investigated 23 TAFE institutes in Victorian State, Australia using the two-stage DEA method for a single year dataset in 1995. Another study is of Fieger et al. (2017) that investigated the efficiency of teaching load and employment outcomes on two separate dimensions for 56 TAFE institutions in Australia, using the stochastic frontier analysis for a single year of 2011. The authors found significant inefficiencies in the VET system for both models and these inefficiencies could be affected by external factors e.g. remote locations, a higher percentage of males, and a larger proportion of individuals from non-English speaking backgrounds. However, by using a single year dataset for the efficiency analysis, these studies did not capture changes in the efficiency of TAFE institutes over time and also not reflect the linkage between teaching outcomes and industry responsiveness in a unified framework to provide an overall picture on the efficiency of the VET system. One of the VET reform initiatives implemented by the Australian Industry and Skills Committee (AISC) which were agreed to by CISC (COAG (Council of Australian Governments) Industry and Skills Council) in November 2015 is to improve the efficiency of the training system by creating units that can be owned and used by multiple industry sectors (National Centre for Vocational Education Research (NCVER) 2017, p.1).

The current paper aims to break new ground in the embryonic efficiency literature of VET by investigating the efficiency of the Australian VET system using a dynamic data envelopment analysis (DEA) network method. It is widely recognised that VET and higher education have a key role to play in preparing future workers for an increasingly complex world of work (Australian Industry Group (AIG) AlphaBeta et al. 2020). For example, the impact of changes at the workplace in the industrial era 4.0 led to several changes in VET so that the graduates remain relevant according to market demand and are ready for their work (Yudiono, et al. 2021). In this regard, the findings of our paper made important contributions to the VET sector in Australia and could potentially be generalised for other countries such as New Zealand, Malaysia, Indonesia and the others on various aspects. Specifically, we assess the VET training efficiency in relation to industry responsiveness in a unified framework. This allows one to investigate divisional-, period- and overall efficiency of the entire VET system. Additionally, using fields of education as decision-making units provides managers and policy makers more insights of how the system works via the linkage between teaching outcome and industry responsiveness. 
The organisation of this paper includes the following sections. "Australian Vocation Education and Training" Section presents a brief review on the Australian VET system. "Measuring efficiency in the education and VET sector" Section introduces measuring efficiency in the VET sector. "Method of analysis" Section demonstrates the theoretical method of dynamic network DEA approach. This is followed by "Empirical strategy and data sources" Section, showing the empirical strategy applied for the VET fields of education. Section 6 presents the estimated results from the empirical model. Discussions are presented in "Discussion" Section before ending with conclusions in "Conclusion" Section.

\section{Australian vocation education and training}

The Australian VET sector is grounded on agreements of diverse partnerships including the Commonwealth, state and territory governments and industry, in which governments contribute to the sector via providing funding and developing policies, regulations, and quality assurance of the sector whereas business and industry contribute to training policies and priorities including qualification development to deliver skills to the workforce (Joyce 2019; NCVER, 2017). In 2012, the Australian VET sector has had around 4,500 training providers. However, in 2017 this figure was 4193 training providers, declined by $7 \%$ from 2012. Regarding government funded subject enrolments, there was 13.5 million funded by Commonwealth or state governments, a $6.3 \%$ decline from 2016 (NCVER 2019). In 2008, Australian governments agreed to make the public VET funding competitive to both public and private providers. Accordingly, in 2012, approximately $25 \%$ of publicly funding VET enrolments came to private or other nongovernment providers (Toner 2014). However, this figure significantly varied after a half decade. In 2017, the government funded full-year students for TAFE and other government providers accounted for $57.4 \%$, the rest of students were with private or other providers (NCVER, 2019). According to Toner (2014, p. 223), the contracting out of public funding was evaluated to be beneficial but probably cause "a persistent and widespread poor-quality private provision". Supporting this argument, Harris (2015, p.17) stated that by virtue of complicated linkage between VET's position and industry, it inevitably leads to on-going debates about the VET's teaching quality from the supporting to the opposite.

Following Australian Skills Quality Authority (ASQA 2019), the VET quality outcome framework is expressed as in Fig. 1. Regardless of the government regulation, policy and funding programs that belong to responsibilities of state organisations to facilitate the training process, the linkage among providers, learners and industry and employers plays a crucial role to enhance the VET quality outcome. These factors have attracted more concern of scholars and researchers in recent years, for example the reform in VET's training quality and regulatory framework (Braithwaite 2018, 2017; Berwyn and Roger 2018; Clayton and Harris, 2018; Harris 2015), changes in funding of VET and effects (Burke 2018), VET's long-term outcomes (Polidano and Ryan 2016), VET's efficiency on teaching load and employment outcome (Fieger et al. 2017), VET's contracting-out public funding (Toner 2014), and impact of VET (Harris and Clayton 2010). However, little research focuses on the training efficiency that links between industry and VET provision. The operational nature of VET and the recent reform taskforces indicate that the 


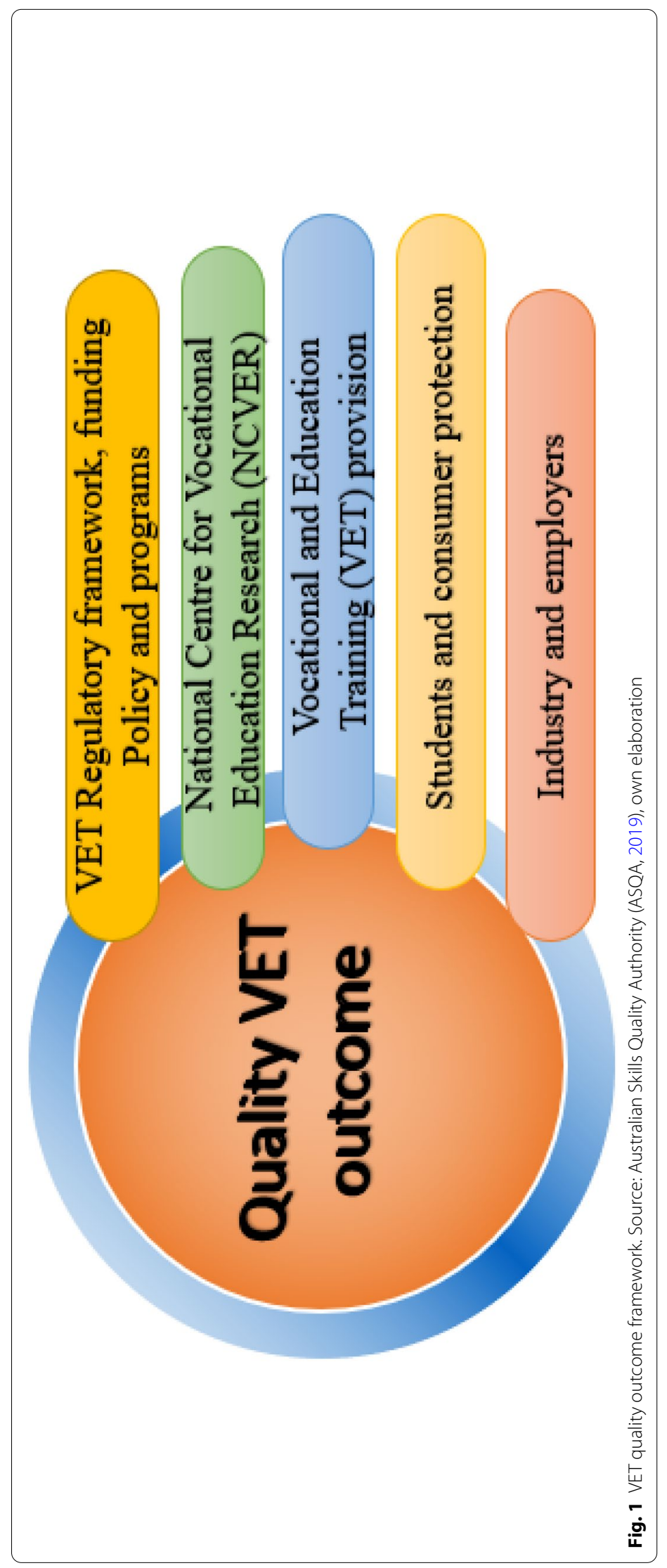


linkage between the efficiency of VET provision and industry responsiveness are important to contribute to the VET quality outcomes, and thus should have received more concern in empirical research. This could provide more useful insights for policy makers for the aim of strengthening the VET's training quality.

The training activities of VET focus on twelve (12) various fields of education that meet specific industry needs as reported in annual reports of Department of Industry before 2013 and in the reports of NCVER afterwards. The enrolment and completion rates for these fields of education are depicted as in Figs. 2 and 3.

It can be seen that the number of enrolments in VET sharply decreased in 2010 and 2012 from 2008. Although there was a significant change among the involved years, the enrolment pattern of 12 fields of education is quite similar. Specifically, the largest figures of enrolments focus on Engineering related Technology, Management and Commerce, and Food, Hospitality and Personal services that might relate to specific industry demands in a particular year. However, Fig. 3 provides an interesting picture about the completion rate. The highest rate of completion focuses on Natural and Physical Science, Education and Society and Culture. It is sluggish that whether this change is due to learners' ability or change in specific industry needs. However, this volatility would affect the teaching efficiency of VET.

Industry responsiveness measured via employer's overall satisfaction on all aspects of VET has been recorded via the survey as shown in Table 1. Industry responsiveness is proxied as an indicator for the effectiveness of VET. In terms of VET's diverse nature, teaching outcomes and industry responsiveness are closely linked to reflect the efficiency and quality of education and training. Accordingly, employer's satisfaction is considered as a key enhancer to the VET education quality. As can be observed, industry satisfaction varied across fields of education. On average $78 \%$ of businesses were satisfied with all aspects of VET for 2009 and 2011. However, it is surprising that the proportion was lower at $63.5 \%$ in 2013, the year that the VET reform taskforces was established to conduct the reform process of the sector.

Improving the efficiency of the training system could be reflected via the relationship between teaching process and industry responsiveness. Therefore, assessing the performance of VET should consider both these phases to reflect both the efficiency and effectiveness of the VET system.

\section{Measuring efficiency in the education and VET sector Theory of efficiency}

Efficiency is referred to "Pareto optimality" attained by any decision-making units (DMU) if and only if none of its inputs or outputs can be improved without making some of its other inputs or output worsen (Friedman 2002). However, in real world, the theoretically possible levels of efficiency will not be known. Instead, relative efficiency can be estimated as defined by Cooper et al. (2011, p.3) "A DMU is to be rated as fully (100\%) efficient on the basis of available evidence if and only if the performances of other DMUs does not show that some of its inputs or outputs can be improved without worsening some of its other inputs or outputs".

In terms of perspectives of an education provider, the efficiency refers to a comparison between observed and optimal values of its outputs and inputs. To be more 


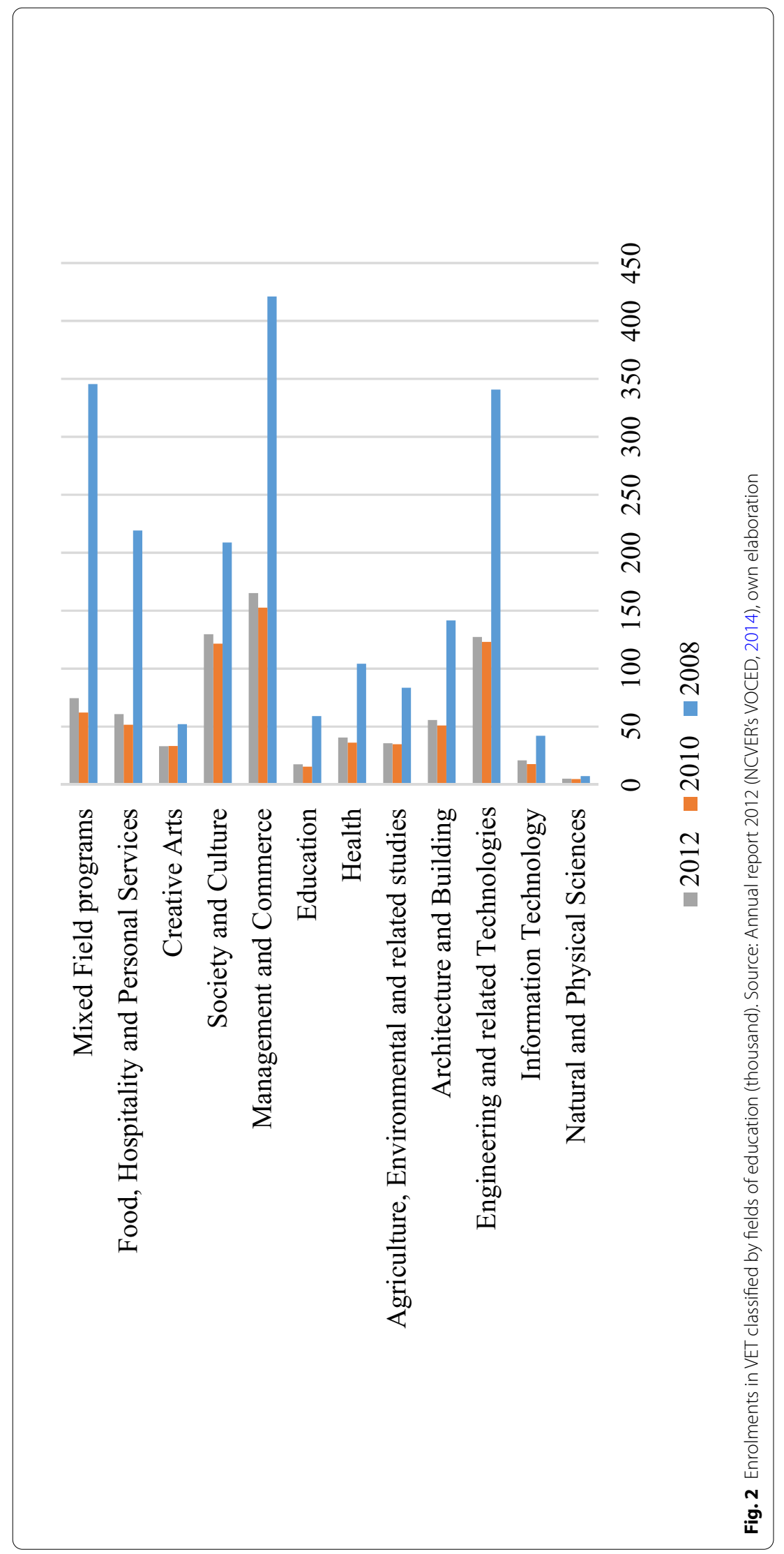




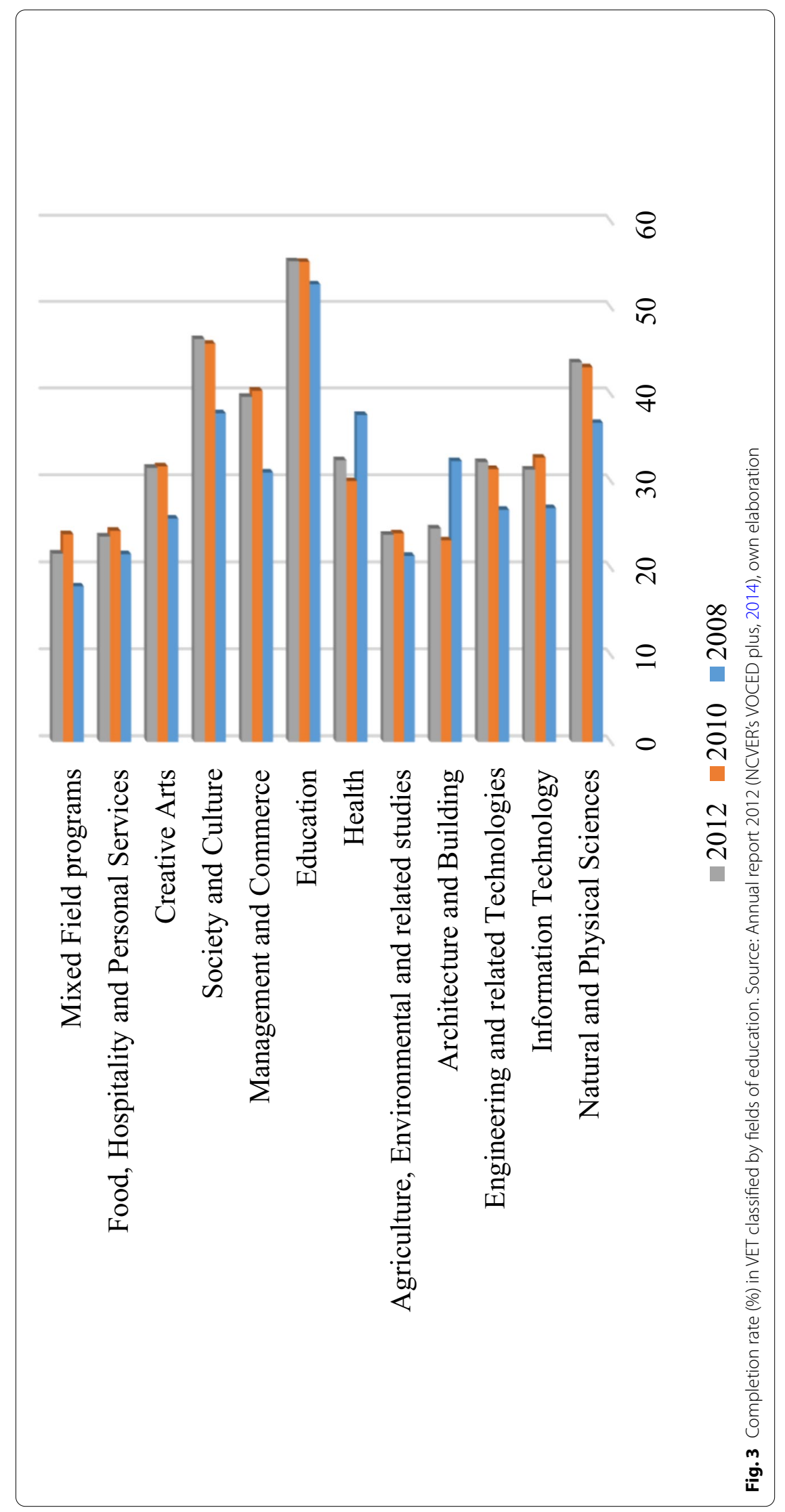


Table 1 Industry satisfaction (\%) on all aspects of VET

\begin{tabular}{llll}
\hline Fields of education & 2009 & 2011 & 2013 \\
\hline Natural and physical sciences & 77.9 & 78.3 & 63.2 \\
Information technology & 85.2 & 66.0 & 59.6 \\
Engineering and related technologies & 74.3 & 79.9 & 62.6 \\
Architecture and building & 80.0 & 81.6 & 62.9 \\
Agriculture, environmental and related studies & 66.3 & 71.8 & 74.0 \\
Health & 84.6 & 75.5 & 67.3 \\
Education & 77.8 & 85.1 & 77.5 \\
Management and commerce & 75.1 & 78.1 & 64.0 \\
Society and culture & 91.4 & 76.0 & 45.8 \\
Creative arts & 77.9 & 89.2 & 65.2 \\
Food, hospitality and personal services & 69.9 & 78.6 & 54.1 \\
Mixed field programs & 77.4 & 80.6 & 66.0 \\
Average & 78.2 & 78.4 & 63.5 \\
\hline
\end{tabular}

Source: NCVER (2019), own calculation

specific, the efficiency level can be measured by comparing observed output to maximum potential output obtainable from the input or by comparing observed input to minimum potential input required to produce the output or some combination of the two. Based on these comparisons, the optimum is determined with respect to production possibilities that depend on the behavioural goal of producers and the efficiency is technical (Fried et al. 2008, p. 8). By virtue of the complex nature of the relation between multiple inputs and multiple outputs involved in the production process, the efficiency analysis of DMUs requires using advanced technique that can deal with large number of variables and constraints (Koksal and Nalcaci 2006).

Data envelopment analysis (DEA) was first developed by Charnes, Cooper and Rhodes (1978) to deal with this problem. DEA is built on the ground of Farrell (1957) who proposed the piecewise-linear convex hull approach to frontier estimation. This method refers to as a data orientated approach for assessing the performance of a set of DMUs, which converts multiple inputs into multiple outputs (Cooper et al. 2011). DEA can distinguish efficient DMUs from inefficient ones and indicate to improvements for each DMU in terms of input and output measures. On top of that, DEA has also showed its importance in measuring relative efficiency of DMUs over regression analysis, ratio analysis, cluster analysis and discriminant analysis (Koksal and Nalcaci 2006). Moreover, DEA has appealed researchers because it does not require information about the price where the price factor in some cases is not available e.g. public management and administration (Tran and Villano 2017). However, this method does not allow one to separate inefficiency from noise (Jacobs 2001).

DEA models are classified by two types of constant returns to scale (Charnes et al. 1978, so-called the CCR model) and variable returns to scale (Banker, Charnes and Cooper 1984, the BCC model). The CCR model is appropriate when all DMUs are operating at an optimal scale, not being affected by the size (e.g. number of students, staff, etc....) (Coelli, Rao, O'Donnell and Battese 2005; Tran and Villano 2017). On the other hand, the BCC model considers scale effects in the analysis under the assumption that imperfect competition, government regulations and constraints on finance 
could potentially affect the optimal operating scale of individual DMUs (Coelli et al. 2005).

The CCR and BCC DEA models are then categorised into the two orientations, input versus output according to the type of proportional movement towards the efficient frontier. The input orientated model refers to the input quantities can be proportionally reduced without changing the output quantities produced whereas the output orientated model aims to estimate how much output quantities can be proportionally expanded without alternating the input quantities used (Coelli et al. 2005; Koksal and Nalcaci 2006). The linear programming equations of the CCR and BBC DEA models are presented in the Appendix A1.

It can be observed that DEA is considered as an excellent method to estimate efficiency of DMUs because it can deal with multiple inputs and outputs without requiring information about the price and having prior assumptions about the functional form between inputs and output. It is noted that identifying the inputs and outputs in real-world assessments of DMUs is difficult, but it is of vital significance. Basically, the inputs should reflect all resources that affect the outputs. On the other hand, the outputs should demonstrate all outcomes that can be used to assess the performance of DMUs (Thanassoulis et al. 2011). Because each sector uses different inputs to produce outputs in their production process, the choice of inputs and outputs would depend on characteristics and specific objectives of each sector to estimate efficiency of DMUs.

\section{Efficiency estimation in the education and VET sector}

Measuring efficiency in the education sector in general and in the VET sector in particular has attracted voluminous studies at different levels of education. However, the production function for the education sector is still blurred. There is no agreement on the selection of inputs and outputs to measure the performance efficiency of the educational institutions using quantitative methods because of its multi-faceted nature, diversity and complexity (Engert 1996; Cordero-Ferrera et al. 2008; Tran and Villano 2017).

The education output, which is generated from a complex production process influenced by many factors, some beyond the control of DMUs is multi-dimensional and difficult to measure. For example, university outputs can be grouped into teaching, research and services; however identifying true measures for these dimensions is not easy because many indicators are not able to be estimated in monetary terms such as qualification of academic staff, quality of published papers and quality of students (Avkiran 2001; Carrington, Coelli, and Rao 2005; Emrouznejad and Thanassoulis 2005). Accordingly, defining a generic production function for the education sector that accurately comprise all relevant aspects of the school/institution production process is exceptionally difficult. As a result, making it possible to measure efficiency through selecting a detailed set of desired outputs, if they can be reasonably manifested by inputs.

De Witte and López-Torres (2017) conducted a comprehensive literature review on efficiency of education and indicated four types of inputs used in efficiency analysis including students' level, family-related factors, education institution and community variables. Among these four categories, the education institution group including personnel (staff, size of students, ratio of academic staff to students, etc.), expenditures, physical capital or resources are commonly used as inputs in efficiency studies of 
education institutions at the tertiary level (e.g. universities, colleges, vocational institutions). Put it differently, the agreed inputs of educational institutions can be grouped as human and physical capital (Linsay 1992; Johnes 1996). O’Donnell et al. (2017) noted that expenditure for academic and professional staff should be excluded if personnel is used as an input to avoid overlap in estimation.

Regarding outputs, there is a greater agreement on specifying output types used in educational efficiency studies. De Witte and López-Torres (2017) summarised four categories such as student achievement (e.g. number of graduates, student test scores for high/primary schools), publications and research activities (for universities and/or colleges), education results (e.g. attendance, drop out, revenues, etc.) and job market success (employability or job satisfaction). These outputs focus on education outcomes at short-, mid- or long- term depending on policies and objectives in higher education (Bessent et al. 1982; Worthington 2001). A recent tendency of studies is to have concentrated on long-term education benefits such as employability, the starting salary of graduates or job satisfaction.

On the other hand, choosing inputs and outputs should reflect the need of industry and the setting examined and follow the accepted theory in different fields that provides a ground of selecting inputs and outputs (Castano and Cabanda 2007). As in other education institutions, the production theory of education institutions should show the relationship between inputs and outputs in their production process. One of salient features of VET institutions is a close linkage between training and industry. VET providers are known as being registered training organisations (RTO) to deliver nationally recognised training or a nationally accredited VET course. Meanwhile, industry and employers may employ students while they undertake a VET course (sometimes through a traineeship or apprenticeship pathway) or employ VET graduates (ASQA 2019). In this regard, outputs and inputs in the production function of VET should reflect a close relationship between VET providers and industry and employers via the linkage of teaching phase and industry responsiveness. The teaching phase refers to providing knowledge and vocational skills to students and ensure that students can be qualified to work in corresponding industries whilst industry responsiveness refers to industry and employers' overall satisfaction after recruiting the trained workforce of VET institutions. The behavioural assumption for this linkage is that industry and employers use the VET graduates, trainees or apprentices and give feedback to VET providers in terms of their satisfaction on different aspects. The responses of industry and employers to the quality of VET output often occur in a following year after VET graduates are employed by industry and employers (NCVER's VOCED 2014).

With respect to this process, the teaching phase requires inputs (e.g. students) to produce the academic output (e.g. graduates). Then, this output becomes an indispensable input to the industry and the output of this phase is a set of responses of industry, demonstrating industry satisfaction to the education quality of VET. In addition to the main linkage between teaching and industry responsiveness, some other factors may affect the process that could increase or decrease efficiency of sub-divisions. Accounting for these factors is necessary to provide robust estimation of efficiency of the VET system.

While efficiency in universities and schools has been flourishingly conducted, studies on efficiency of Australian VET institutions have been quite nascent. To our knowledge, 
the first work proposed by Abbott and Doucouliagos (2002) investigated 23 Technical and Further Education (TAFE) in Victorian State, using the two-stage DEA method for a single year of 1995 . The results revealed that Victorian TAFE institutes were inefficient in their operation and their technical and scale efficiencies demonstrated substantial dispersion. Regression analysis was used to identify external variables which are associated with technical inefficiency such as class size, administrative staff, government funding and others. More recently, Fieger et al. (2017) examined the efficiency of the Australian VET system in two separate dimensions, teaching load and employment outcome, using stochastic frontier analysis. This study used the data for 56 TAFE institutions for the single year of 2011. The authors found that the efficiency scores of teaching load and employment outcomes are 0.904 and 0.93 , respectively, and that these scores are affected by characteristics of inputs and control variables. However, studying separately two nodes, teaching load and employment outcome, as shown in Fieger et al. (2017) would not explore in depth the linkage between them to contribute to efficiency of the entire VET training process. In addition, the dynamic change over time, which is of important factors of interest was not covered in their research. Put it differently, research on the training efficiency of VET need to be focused on the link between the teaching phase and industry responsiveness in a unified context as indicated in the objectives of the VET reform agenda. This is because a change occurred in either phase would impact on the overall training efficiency.

This paper seeks to bridge the gap as mentioned above in the nascent literature of efficiency of the VET sector by using the dynamic network data envelopment analysis (DEA) approach and its theoretical model is presented in the next section.

\section{Method of analysis}

It is widely recognised that using the DEA model to estimate efficiency in the education sector has been well-documented in the literature in terms of its advantages such as dealing with multiple outputs and inputs at the same time that could be exempted from price information and from not requiring prior functional form between inputs and outputs (Johnes and Yu 2008; Jacob 2001; Tran and Villano 2017). The conventional DEA models as presented in the appendix can provide efficiency scores of DMUs of interest in terms of determined inputs and outputs. However, if using such conventional DEA only, an internal network that links operations of different stages could potentially be neglected (Tran and Villano 2018a). Instead, a network DEA method proposed by Tone and Tsutsui (2009) can be used to fill this gap by investigating performance of transitional stages for the aim of seeking appropriate solutions to improve efficiency for each stage in the production process of firms, for example efficiency of two divisions, teaching and employability of students, teaching and research nodes (Monfared and Safi 2013), research and grant application stages (Lee and Worthington 2016).

To capture dynamic changes of divisional efficiency over time, Tone and Tsutsui (2014) developed a dynamic network DEA based on the grounds of the dynamic DEA model with network analysis structure (Tone and Tsutsui 2009) in a unified framework, for example the teaching phase and industry responsiveness in the VET sector. This dynamic network model was used in recent studies of Tran and Villano (2018a, b) to measure the overall efficiency of Vietnamese public HEIs, academic and financial efficiencies and dynamic 
variation in the efficiency of these divisions over surveyed periods. Their results revealed that the financial efficiency contributed significantly to the overall efficiency of public institutions (colleges and universities) rather than the academic efficiency. In educational perspectives, their studies have focused on internal links within institutions' operations without accounting for industry's responses in terms of employer's satisfaction that demonstrates effectiveness of the education and training process. It appears that the final node to complete this process is missing.

In the current paper, the dynamic network slack-based DEA output orientated model is used to estimate teaching efficiency in relation to industry responsiveness of the Australian VET system in a unified framework. This paper expectedly makes the following contributions to the literature. First, this study is the first to assess the overall training efficiency of VET in a dynamic network slack-based DEA output orientated method (DNDEA), particularly focusing on the field of education-based dynamic training efficiency resulted from intermediate activities of different stages in an overarching framework. Second, research on efficiency in divisional teaching and industry responsiveness (proxied by employers' satisfaction) in a network structure is also the first to be conducted in VET that allows one to estimate independently the efficiency of teaching division and industry responsiveness. Finally, the importance of each division in the unified structure is examined for policy implications.

Using the model proposed by Tone and Tsutsui (2014), assume that $n$ DMUs, in this paper the fields of education (FOE, $\mathrm{n}=12)(j=1, \ldots, n)$ including $D$ divisions $(\mathrm{D}=2)$ $(d=1, \ldots, D)$ over $\mathrm{T}$ time periods $(\mathrm{T}=3)(t=1, \ldots, T)$. The numbers of inputs and outputs to division $d$ are denoted as $k_{d}$ and $h_{d}$ be, respectively, the link leading from division $d$ to division $r$ by $(d r)_{i}$ and the set of links by $L_{d r}$. In the same vein, we defined the inputs, outputs, linking and carry-over variables as follows:

Input resource $i$ to $D M U_{j}$ for division $d$ in period $t: x_{i j d}^{t} \in S_{+}\left(i=1, \ldots, k_{d} ; j=1, \ldots\right.$, $D ; t=1, \ldots, T)$;

Output product $\mathrm{r}$ from $D M U_{j}$, division $d$, in period $t: y_{r j d}^{t} \in S_{+}\left(r=1, \ldots, h_{d} ; j=1, \ldots\right.$, $D ; t=1, \ldots, T)$;

The linking intermediate products of $D M U_{j}$ from division $d$ to division $r$ in period $t$ : $z_{j(d r)_{l}}^{t} \in S\left(j=1, \ldots, k_{d} ; l=1, \ldots, L_{d r} ; t=1, \ldots, T\right)$, where $L_{d r}$ is the number of items in the link from $d$ to $r$; and.

The carry-over of $D M U_{j}$, at division $d$, from period $t$ to period $t+1$ : $\omega_{j d_{l}}^{(t, t+1)} \in R_{+}\left(j=1, \ldots, k_{d} ; l=1, \ldots, l_{d} ; d=1, \ldots, D ; t=1, \ldots, T-1\right)$, where $L_{d}$ is the number of items in the carry-over from division $d$.

The production possibility set $Q^{t}=\left\{\left(x_{d}^{t}, y_{d}^{t}, \omega_{(m r)}^{t}, \omega_{i d}^{(t, t+1)}\right)\right\}(t=1, \ldots, T)$ is expressed by.

$$
\begin{gathered}
x_{d}^{t} \geq \sum_{j=1}^{n} x_{j d}^{t} \lambda_{j d}^{t}(\forall d, \forall t) \text { and } y_{d}^{t} \leq \sum_{j=1}^{n} y_{j d}^{t} \lambda_{j d}^{t}(\forall k, \forall t) \\
\omega_{(d r)_{t}}^{t}=\sum_{j=1}^{n} \omega_{j(d r)_{t}}^{t} \lambda_{j d}^{t}\left(\forall l, \forall(d r)_{l}, \forall t\right)(\text { as outputs from d in period } t)
\end{gathered}
$$




$$
\begin{aligned}
& \omega_{(d r)_{t}}^{t}=\sum_{j=1}^{n} \omega_{j(d r)_{t}}^{t} \lambda_{j r}^{t}\left(\forall l, \forall(d r)_{l}, \forall t\right)(\text { as inputs from r in period } t) \\
& \omega_{d_{l}}^{t(t+1)}=\sum_{j=1}^{n} \omega_{j d_{r}}^{t(t+1)} \lambda_{j d}^{t}\left(\forall l, \forall(d r)_{l}, \forall t\right)(\text { as carry over from period } t) \\
& \omega_{d_{l}}^{t(t+1)}=\sum_{j=1}^{n} \omega_{j d_{l}}^{t(t+1)} \lambda_{j d}^{t+1}\left(\forall l, \forall(d r)_{l}, \forall t\right)(\text { as carry over to period } t+1) \\
& \sum_{j=1}^{n} \omega_{j d}^{t}=1(\forall d, \forall t), \lambda_{j d}^{t} \geq 0(\forall j, \forall k, \forall t)
\end{aligned}
$$

where $\lambda_{d}^{t}=\left\{\lambda_{j d}^{t}\right\} \in S_{+}^{n}$ is the intensity vector corresponding to division $d, \forall d a t t, \forall t$.

It is noted that no linking and carry over variables from the previous period and, at the terminal period, $\mathrm{T}$ are assumed at the initial period $\mathrm{T}_{1}$. Similarly, no linking output from the terminal division and no carry-over to the next period are present in the model.

Regarding input-output constraints, for $\mathrm{DMU}_{\mathrm{o}} \quad(o=1, \ldots, n \in Q)$, $x_{o d}^{t}=X_{d d}^{t t}+s_{d o}^{t-}(\forall d, \forall t) ; \quad y_{o d}^{t}=Y_{d d}^{t t}-s_{d o}^{t+}(\forall d, \forall t), \quad$ and $\quad e_{d}^{t}=1(\forall d, \forall t)$, where $\quad{ }_{d}^{t} \geq 0, s_{d o}^{t-} \geq 0, s_{d o}^{t+} \geq 0(\forall d, \forall t) ; \quad$ and $\quad X_{d}^{t}=\left(x_{1 d}^{t}, \ldots, x_{n d}^{t}\right) \in S^{k_{d} \times h} \quad$ and $Y_{d}^{t}=\left(y_{1 d}^{t}, \ldots, y_{n d}^{t}\right) \in S^{h_{d} \times n}$-input and output matrices, and $s_{k o}^{t-}$ and $s_{k o}^{t+}$ are, respectively, input and output slacks.

As for the linking constraints, the linking variables are treated as the input-link in this paper to the next division. That is to say, excesses are attributed as the input inefficiency and demonstrated as $\omega_{o(d r) i n}^{t}=\omega_{(d r) i n d}^{t}+s_{o(d r) i n}^{t}\left((d r) i n=1, \ldots\right.$, linkin $\left._{d}\right)$, where $s_{o(d r) i n}^{t} \in S^{L}(d r)$ in are slacks and non-negative, and linkin $_{d}$ is the number of asinput link from division $\mathrm{d}$.

The carry over used in this paper can be handled freely, meaning that its value can rise or reduce from the observed one and that the deviation from the current value does not directly reflect in the efficiency scores (Tone and Tsutsui 2014, pp.126-127). The carry over constraint is depicted as follows:

$$
\omega_{o d_{l} C A R R Y}^{t(t+1)}=\sum_{j=1}^{n} \omega_{j d_{l} C A R R Y}^{t(t+1)} \lambda_{j d}^{t}+s_{o d_{l} C A R R Y}^{t(t+1)}\left(d_{l}=1, \ldots, n C A R R Y_{d}, \forall k, \forall t\right)
$$

In this study, the output-orientated approach is used to measure the FOE-based training efficiency of VET. This is assumed that Australian VET aims to maximise the completion rate and industry satisfaction. The overall-, period- and divisional-efficiencies are depicted by the following formulae:

Overall efficiency

$$
1 / \theta_{o}^{*}=\operatorname{Max} \sum_{t=1}^{T} W^{t}\left[\sum_{d=1}^{D} w^{k}\left[1+\frac{1}{h_{d}+\text { linkin }_{d}+n C A R R Y_{d}}\left(\sum_{i=1}^{h_{d}} \frac{s_{i o d}^{t+}}{y_{i o i}^{t}}+\sum_{d r_{t}=1}^{\operatorname{linkin}_{d}} \frac{s_{o(d r)_{i} i n}^{t}}{z_{o\left(d r_{i} i n\right.}^{t}}+\sum_{d_{t}=1}^{n \operatorname{CARRY}_{d}} \frac{s_{o d_{i} \text { CARRY }}^{t(t+1)}}{\omega_{o d_{i} C A R R Y}^{t(+1)}}\right)\right]\right]
$$


Period efficiency

$$
1 / \tau_{0}^{t *}=\sum_{d=1}^{D} w^{d}\left[1+\frac{1}{h_{d}+\text { linkin }_{d}+n \text { carry }_{d}}\left(\sum_{i=1}^{k_{d}} \frac{s_{i o d}^{t+}}{y_{i o d}^{t}}+\sum_{d r_{t}=1}^{\text {linkin }_{d}} \frac{s_{o(d r)_{i} i n}^{t}}{\omega_{o(d r)_{i} i n}^{t}}+\sum_{d_{t}=1}^{n C A R R Y_{d}} \frac{s_{o d_{i} \text { CARRY }}^{t(t+1)}}{\omega_{o d_{i} C A R R Y}^{t(t+1)}}\right)\right]
$$

Divisional efficiency

$$
1 / \delta_{0}^{t *}=\sum_{t=1}^{T} W^{t}\left[1+\frac{1}{h_{d}+\text { linkin }_{d}+n C A R R Y_{d}}\left(\sum_{i=1}^{h_{d}} \frac{s_{i o d}^{t+}}{y_{i o d}^{t}}+\sum_{d r_{t}=1}^{\text {linkin }_{d}} \frac{s_{o(d r)_{i} i n}^{t}}{\omega_{o(d r)_{i} i n}^{t}}+\sum_{d_{t}=1}^{n C A R R Y_{d}} \frac{s_{o d_{i} C A R R Y}^{t(t+1)}}{\omega_{o d_{i} C A R R Y}^{t(t+1)}}\right)\right]
$$

Finally, period-divisional efficiency is defined as

$$
1 / \rho_{0}^{t *}=1+\frac{1}{h_{d}+\operatorname{linkin}_{d}+n C A R R Y_{d}}\left(\sum_{i=1}^{h_{d}} \frac{s_{i o d}^{t+}}{y_{i o d}^{t}}+\sum_{d r_{t}=1}^{\text {linkin }_{d}} \frac{s_{o(d r)_{i} i n}^{t}}{\omega_{o(d r)_{i} i n}^{t}}+\sum_{d_{t}=1}^{n C A R R Y_{d}} \frac{s_{o d_{i} C A R R Y}^{t(t+1)}}{\omega_{o d_{i} C A R R Y}^{t(t+1)}}\right)
$$

It is noted that in the output-orientated model, the overall training efficiency is computed as the weighted arithmetic mean of the period/node efficiencies. The weights for each node/period should be opted to ensure uniqueness issue in efficiency (Tone and Tsutsui 2014). The application of this DNDEA model in the VET system is presented in the next section.

\section{Empirical strategy and data sources}

\section{Empirical analysis of the network dynamic DEA model}

In this paper, two major phases emphasised in the training process of the Australian VET system are teaching and industry responsiveness that reflect training outcomes and overall satisfaction of employers who use graduates as a job requirement. These phases demonstrate the importance of a completed production process via a close linkage between training and industry.

Following the theoretical background as presented in "Method of analysis" Section , we used the fields of VET education as DMUs. These fields of education then are analysed in a framework of two phases/notes, teaching and industry responsiveness (industry satisfaction) for multiple periods of three years $(T=3)$. It can be observed that the key aim of the teaching phase is to train students with the final satisfied outcome for the whole program and/or the subjects pass. This phase is important to provide good-qualified workforce as an input to industry and employers via job requirements, thus contributes to the workforce market in Australia. On the other hand, the main objective of the industry responsiveness phase is to use the VET graduates as employees and reflect employers' overall satisfaction on employees' working outcomes. Both phases depict an overall picture of the training process of VET providers from school to practice that would provide more insights for institutions and policy makers to move the sector forward. To do this, other than the conventional DEA, the advanced DNDEA method can explore in depth the efficiency of each phase and capture its dynamic changes over multiple periods.

Figures 4 presents the empirical model to estimate the dynamic training efficiency of VET. Selecting inputs and output variables play an important role in the VET performance analysis. As discussed earlier, selecting inputs and outputs should reflect the need and objective of the industry. 


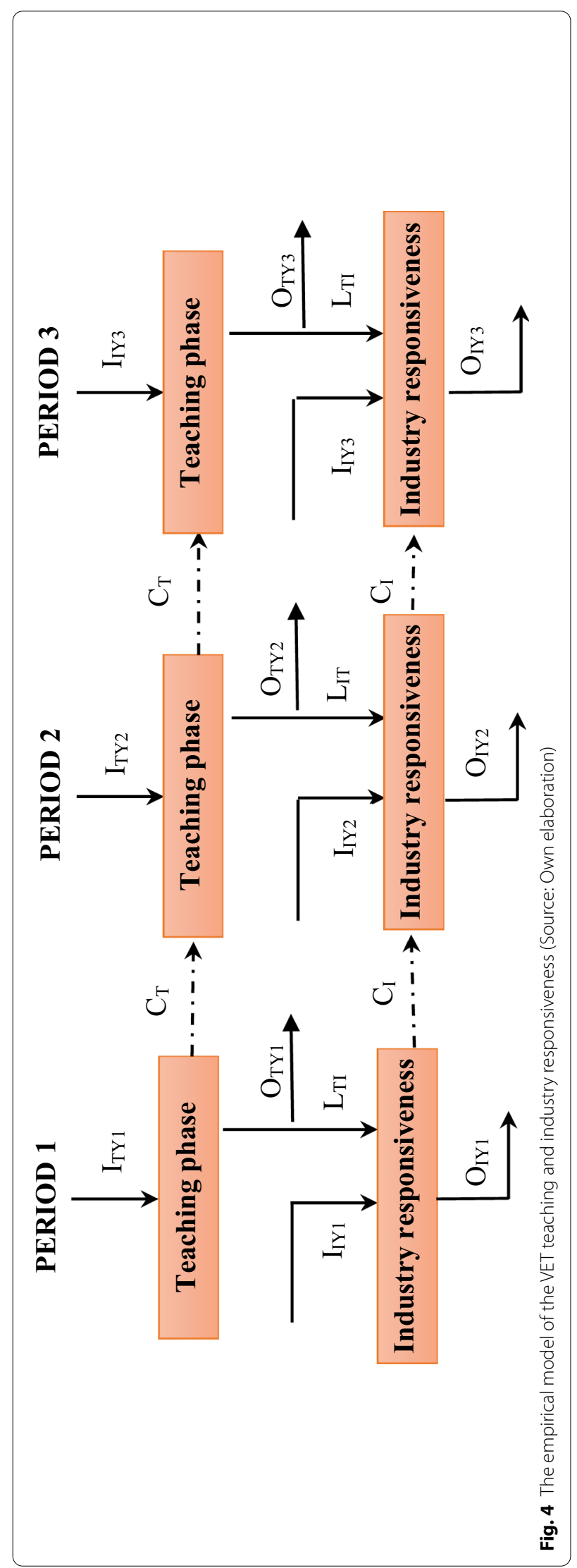


For the teaching phase, the objective of VET is to educate and train the students in a short- or mid-term period to successfully obtain their diploma or certificate. Whilst teaching phase may depend on different factors such as teaching staff, administrative staff, facilities, in this paper, we used student numbers who enrolled in each field of education can be considered as a proxy of input for the training and education process of $\operatorname{VET}\left(\mathrm{I}_{\mathrm{T}}\right)$. Consequently, the output for this process is proxied by the qualification completion rate $\left(\mathrm{L}_{\mathrm{r}}\right)$ that reflects the proportion of students who finish the qualification they started and are ready for industry engagement. In addition, the subject load pass rate is added in this phase as an output $\left(\mathrm{O}_{\mathrm{r}}\right)$. The subject pass rate is the ratio of hours studied by students who passed their subjects to the total hours committed to by all students who passed, failed or withdrew from the corresponding subjects (NCVER's Vocational Education and Training Research Database (VOCED) 2014). This rate is used as a proxy to mirror the learning quality of students.

For the industry satisfaction/responsiveness phase, the objective of VET is not only to provide a qualified workforce to the industry but also expect to get the industrial employers involved into the VET process as an important input $\left(\mathrm{I}_{\mathrm{I}}\right)$. The proportion of employer engagement (e.g. study or having employees to learn at VET institutions) would provide richer information about effectiveness of VET. Accordingly, the output for the industry responsiveness phase $\left(\mathrm{O}_{\mathrm{I}}\right)$ is proxied as the satisfaction of employers who assessed efficiency and effectiveness of VET on all aspects.

The intermediate factor linking between two phases of teaching and industry responsiveness is the qualification completion rate $\left(\mathrm{L}_{\mathrm{I}}\right)$. This factor is proxied as the output of the teaching phase and treated as a discretionary free link that can go up or down for each period. The completion rate illustrates the linkage between VET and the industry, being a subject evaluated by the industry. That is to say that industry and employers would reflect the quality of VET based on the quality of graduates.

As for the carry-over between periods, in the teaching phase, the subject non-pass rate $\left(\mathrm{C}_{\mathrm{T}}\right)$ is set as an undesirable carry over factor, meaning that students of each field of education if fail any subjects need to retake it in the next period. This variable is included to reflect the complete operating process of VET to obtain a desired degree or diploma. In the industry responsiveness phase, the percentage of employers using nationally recognised training is opted as a proxy of carry-over $\left(C_{I}\right)$ that not only facilitates for the training process in the current period but for the next period as well. Generally, employers who are using nationally recognised training would show their engagement in VET

Table 2 Description of variables used in the empirical DNDEA model

\begin{tabular}{lll}
\hline Variable & Category & Description \\
\hline Teaching & & \\
$I_{T}$ & Input & Number of enrolments \\
$\mathrm{O}_{T}$ & Output & Subject pass rate \\
$\mathrm{L}_{T}$ & Link & Completion rate \\
$C_{T}$ & Carry-over & Subject non-pass rate \\
Industry satisfaction & & \\
$I_{1}$ & Input & Percentage of employers' engagement in VET \\
$\mathrm{O}_{1}$ & Output & Percentage of employers'satisfaction with all aspects of VET \\
$C_{1}$ & Carry-over & Percentage of employers using nationally recognised training \\
\hline
\end{tabular}


Table 3 Summary statistics of inputs and outputs

\begin{tabular}{lccccccc}
\hline & $\begin{array}{l}\text { Enrolment } \\
\text { ('O00 stds) }\end{array}$ & $\begin{array}{l}\text { Subject Non- } \\
\text { pass rate (\%) }\end{array}$ & $\begin{array}{l}\text { Completion } \\
\text { rate (\%) }\end{array}$ & $\begin{array}{l}\text { Subject } \\
\text { pass rate } \\
(\%)\end{array}$ & $\begin{array}{l}\text { Employer's } \\
\text { NRT' }(\%)\end{array}$ & $\begin{array}{l}\text { Employer's } \\
\text { engagement } \\
(\%)\end{array}$ & $\begin{array}{l}\text { Employer's } \\
\text { satisfaction } \\
(\%)\end{array}$ \\
\hline Period 1 & & & & & & & \\
Mean & 168.83 & 20.84 & 30.69 & 79.49 & 29 & 53.84 & 85.64 \\
Stdev & 137.69 & 7.73 & 9.58 & 7.39 & 10 & 14.73 & 5.74 \\
Minimum & 7.40 & 14.60 & 17.90 & 59.90 & 17 & 27.00 & 72.10 \\
Maximum & 421.10 & 40.10 & 52.70 & 86.00 & 48 & 79.00 & 94.50 \\
Period 2 & & & & & & & \\
Mean & 58.73 & 20.51 & 33.82 & 79.98 & 28 & 54.08 & 85.08 \\
Stdev & 47.91 & 7.39 & 10.26 & 6.88 & 11 & 16.34 & 3.45 \\
Minimum & 4.9 & 14 & 23.2 & 61.8 & 13 & 31.1 & 79.6 \\
Maximum & 152.6 & 40.1 & 55.3 & 86.3 & 49 & 81 & 91.6 \\
Period 3 & & & & & & & 76.67 \\
Mean & 63.86 & 20.02 & 33.85 & 80.45 & 26 & 54.73 & 8.72 \\
Stdev & 50.98 & 6.88 & 10.47 & 7.00 & 12 & 14.28 & 56.50 \\
Minimum & 5.10 & 13.70 & 21.67 & 62.30 & 15 & 28.50 & 92.60 \\
Maximum & 165.30 & 38.20 & 55.37 & 86.37 & 60 & 74.90 & \\
\hline
\end{tabular}

${ }^{a}$ NRT denotes employers using nationally recognised training

and industry responsiveness. Description of discussed factors for the analysis process are shown in Table 2.

The number of inputs and outputs used for each phase should be carefully considered to ensure the power of analysis and thus produce unbiased efficiency scores. According to Banker, Charnes, and Cooper (1984), a sum of inputs and outputs can be used in DEA models should be less than or equal to the one-third of total observations. Accordingly, for each phase in our model, total inputs and outputs should be no more than 4 in terms of 12 fields of education. Based on this rule, inputs and outputs including linking and carry-over variables for each phase are appropriately chosen to reflect the nature of teaching process and industry satisfaction. A statistical summary on all variables used in the DNDEA model is shown in Table 3.

As indicated in Tone and Tsutsui (2014), weights for periods and nodes need to be pre-determined in the DNDEA model. In 2012, the VET reform taskforce was set up to implement the reform objectives proposed by the Council of Australian Governments (COAG) VET reform agenda. This year becomes important for the teaching efficiency and industry responsiveness, thus would be set at a higher level than other previous years. That is, the year 3 has the top priority and those of the years 2 and 1 decrease in this order. As reflected in the key initiatives of the VET reform (NCVER, 2017), teaching and industry responsiveness play a crucial role in the VET reform, thus carry equal importance for the training process of VET. Weights for nodes and periods are presented in Table 4.

\section{Data and data sources}

Previous studies in education efficiency traditionally used institutions as assessed units that could potentially lack inclusion of all institutions in analysis due to insufficient data. To avoid this, the present paper aims to use all VET fields of education instead that could 
Table 4 Weights for periods and nodes

\begin{tabular}{lllc}
\hline Period & Weight & Nodes & Weight \\
\hline 1 & 0.25 & Teaching phase & 0.5 \\
2 & 0.30 & Industry satisfaction & 0.5 \\
3 & 0.45 & & \\
\hline
\end{tabular}

Table 5 Efficiency analysis of the training process in the Australian VET system

\begin{tabular}{llllll}
\hline Efficiency of the VET system & Mean & $\begin{array}{c}\text { Standard } \\
\text { deviation }\end{array}$ & Min & Max & Efficient fields \\
& & & & & \\
\hline The whole system (period divisional network efficiency) & & & & \\
Period 1 & 0.851 & 0.071 & 0.73 & 0.942 & 0 \\
Period 2 & 0.867 & 0.079 & 0.77 & 1 & 2 \\
Period 3 & 0.806 & 0.096 & 0.67 & 1 & 1 \\
Overall period-divisional network efficiency & 0.835 & 0.073 & 0.746 & 0.982 & 0 \\
Hotelling test for efficiency of three periods & $3.1^{*}$ & & & & \\
Teaching phase (Divisional efficiency) & & & & & \\
Period 1 & 0.785 & 0.186 & 0.46 & 1 & 4 \\
Period 2 & 0.782 & 0.161 & 0.539 & 1 & 3 \\
Period 3 & 0.738 & 0.161 & 0.507 & 1 & 2 \\
Period-divisional teaching efficiency & 0.763 & 0.153 & 0.505 & 1 & 2 \\
Hotelling test for efficiency of three periods & 0.83 & & & & \\
Industry responsiveness (IR, Divisional efficiency) & & & & & 5 \\
Period 1 & 0.916 & 0.101 & 0.665 & 1 & 5 \\
Period 2 & 0.953 & 0.086 & 0.798 & 1 & 9 \\
Period 3 & 0.874 & 0.104 & 0.748 & 1 & 4 \\
Period-divisional IR efficiency & 0.908 & 0.079 & 0.794 & 1 & 3 \\
Hotelling test for efficiency of three periods & $4.27^{* *}$ & & & &
\end{tabular}

** and * denote the significance levels at $5 \%$ and $10 \%$, respectively

reflect performance of the whole industry. Accordingly, the theoretical model described in the above section is applied to all twelve (12) fields of education of the Australian VET system for efficiency analysis. Data analysis is a four-year period, 2008-2012 for the teaching stage, and 2009-2013 for industry satisfaction in a balanced panel dataset. The period for industry satisfaction is lagged one year because the survey of industry satisfaction was collected after students graduated, that is for a every two years period. Data were extracted from annual reports of VET (NCVER's, VOCED. 2014).

\section{Empirical results}

The period-divisional (dynamic) network efficiency of the VET system

This section illustrates the empirical findings of the dynamic network DEA models for the Australian VET sector and individual efficiency scores of 12 fields of education over the surveyed period. The divisional efficiency is estimated for each division, teaching and industry responsiveness. This efficiency score can be estimated for each period, so-called the period efficiency. Then, for all periods, it is called as the period-divisional efficiency for that division. For the whole system in a network structure over the multiple periods, the period and overall period-divisional network efficiencies (so-called the overall 
dynamic network efficiency) are estimated given re-determined weights for each division and each period. Table 5 presents the efficiency scores for two phases and for the whole system in terms of the period efficiency and divisional-period network efficiency.

It can be observed that given pre-determined weights for each phases and period, the average overall period-divisional network efficiency for the VET training is 0.835 . This implies that the Australian VET could potentially improve their efficiency in a network structure of teaching and industry responsiveness by $16.5 \%$. The dynamic change in the efficiency score of VET as determined by the DNDEA model, volatiles across years, rising slightly from period 1 to period 2 , then moderately declining from period 2 to period 3. This instability is due to change in efficiency of individual phases, teaching and industry satisfaction. The Hotelling test shows a significant difference among three periods at less than $10 \%$ level of significance.

The DNDEA model allows us to observe separately changes in efficiency of individual phases. The findings reveal that the period-divisional teaching efficiency is on average 0.763 , meaning that VET needs to improve their teaching efficiency by $23.7 \%$ to obtain the full efficiency of one. In a closer view, there is a decline in the VET teaching efficiency over the reported periods. However, the difference in the period teaching efficiency is not significant at the $5 \%$ level of significance.

Regarding the industry responsiveness, the period-divisional efficiency of the VET system varied minimally over three periods, increasing by $3.7 \%$, from 0.916 in period 1 to 0.953 in period 2 , then declining by $7.9 \%$, to 0.874 in period 3 . This fluctuation has driven the changing trend in the efficiency of the Australian VET system, especially in period 3, when the overall efficiency and the efficiency in industry responsiveness decreased. This may be affected by the VET reform initiatives released in 2012 in which education quality and industry responsiveness are determined as one of reform initiatives. This would influence the completion rate and industry satisfaction. However, whether this decline can be attributed to the influence of the government policy intervention is out of our consideration because deterministic and causal relationships in this context are difficult to identify. Regardless of this scenario, the average efficiency of industry responsiveness is respectable at 0.908 . In other words, there is a room for the VET sector to increase the industry satisfaction level by $9.2 \%$. The Hotelling test indicates that the heterogeneity in period-divisional efficiency of industry satisfaction over three periods is significant at the $5 \%$ level of significance.

Table 6 Correlation matrix for the overall and divisional efficiencies, 2008-2012

\begin{tabular}{llll}
\hline & Overall network & Teaching phase & $\begin{array}{c}\text { Industry } \\
\text { responsiveness }\end{array}$ \\
\hline Overall network $^{\mathrm{a}}$ & 1.000 & 1.000 & 1.000 \\
Teaching phase $^{\mathrm{b}}$ & $0.846^{* * *}$ & -0.32 & 134 \\
Industry responsiveness $^{c}$ & 0.134 & \\
\hline
\end{tabular}

a The overall period-divisional/overall dynamic network efficiency over the period reported

b The period-divisional/dynamic efficiency of teaching phase over the period reported

c The period-divisional/dynamic efficiency of industry responsiveness over the period reported

*** denotes the significance level at $1 \%$ 
The Spearman's rank correlation coefficients among the efficiencies of teaching phase and industry responsiveness and the overall network efficiency (the period divisional network efficiency) over the three periods are presented in Table 6. The findings show that the overall network efficiency is strongly correlated to teaching efficiency with the correlation coefficient of 0.846 at the $1 \%$ level of significance. This implies that teaching efficiency is a key enhancer in the overall efficiency of the VET system. Although the industry responsiveness does not contribute significantly and directly to the efficiency of the VET sector, it plays an indispensable role to assist the VET system to ameliorate their education quality and contribute more effectively to the Australian workforce market. Having a closer look at individual fields of education, it follows that some fields of education are fully efficient in teaching but not in industry responsiveness (employers' satisfaction) for example Education and Natural and Physical Sciences. On the other hand, some fields of education such as Agriculture, Environmental, and related studies and Society and Culture are fully efficient in industry responsiveness, but not in the teaching phase. It is observed that the correlation between teaching and industry responsiveness is negative but not significant at the $5 \%$ level. This implies that the industry satisfaction to teaching efficiency via the quality of graduates had a decreasing trend and needs to be perused carefully.

The distributions of the estimated efficiencies of the VET sector based on the DNDEA model for each phase and the overall system are illustrated in Fig. 5. It can be seen that the efficiency of the teaching phase is strongly related with the overall network efficiency. By contrast, there is a large dispersion in the correlation between efficiency of industry responsiveness and the overall network efficiency. This suggests the importance of teaching phase in the VET efficiency albeit this phase still needs to improve its performance to obtain the full frontier efficiency.

Table 7 demonstrates the individual efficiency and overall efficiency of 12 fields of education over the period involved. The top $25 \%$ percentile includes Society and Culture (0.986), Education (0.982), and Natural and Physical Sciences (0.956) whereas the bottom 25\% percentile consists of Information Technology (0.83), Management and Commerce (0.837), Food, Hospitality and Personal Services (0.78), and Mixed field programs

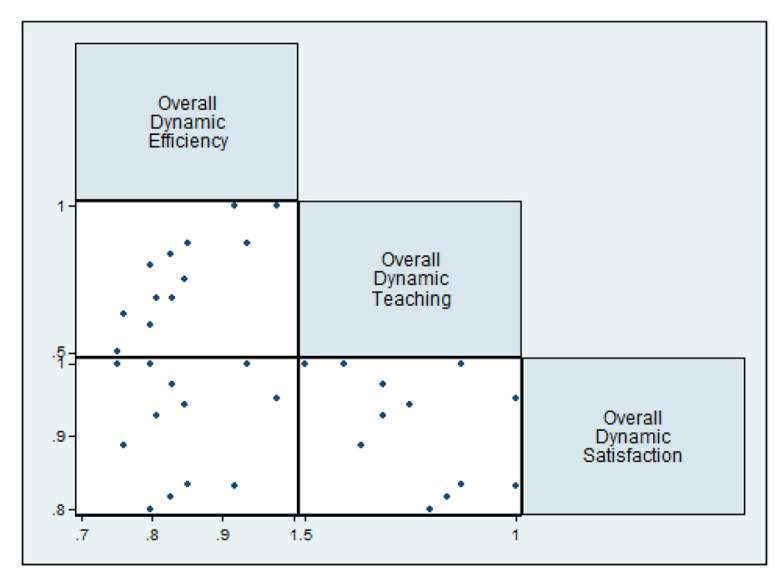

Fig. 5 Scatter plot matrix of the training efficiency in VET 
Table 7 Overall and period efficiency for 12 fields of education

\begin{tabular}{|c|c|c|c|c|c|}
\hline No & Field of education & Period 1 & Period 2 & Period 3 & Overall \\
\hline 1 & Natural and Physical Sciences & 0.942 & 0.914 & 0.894 & 0.956 \\
\hline 2 & Information Technology & 0.844 & 0.845 & 0.730 & 0.830 \\
\hline 3 & Engineering and related Technologies & 0.938 & 0.790 & 0.751 & 0.847 \\
\hline 4 & Architecture and Building & 0.832 & 1.000 & 0.724 & 0.870 \\
\hline 5 & Agriculture, Environmental and related studies & 0.794 & 0.799 & 0.799 & 0.838 \\
\hline 6 & Health & 0.893 & 0.846 & 0.801 & 0.878 \\
\hline 7 & Education & 0.929 & 1.000 & 1.000 & 0.982 \\
\hline 8 & Management and Commerce & 0.784 & 0.814 & 0.795 & 0.837 \\
\hline 9 & Society and Culture & 0.913 & 0.945 & 0.948 & 0.986 \\
\hline 10 & Creative Arts & 0.828 & 0.850 & 0.806 & 0.865 \\
\hline 11 & Food, Hospitality and Personal Services & 0.780 & 0.833 & 0.670 & 0.780 \\
\hline \multirow[t]{2}{*}{12} & Mixed Field programs & 0.730 & 0.770 & 0.754 & 0.790 \\
\hline & Average & 0.851 & 0.867 & 0.806 & 0.835 \\
\hline
\end{tabular}

Estimated in a network structure of teaching phase and industry responsiveness

Table 8 Sensitivity analysis with different cases for period weights

\begin{tabular}{|c|c|c|c|c|c|c|c|}
\hline & \multicolumn{3}{|c|}{ Period weights } & \multicolumn{4}{|c|}{ Overall efficiency scores } \\
\hline & Period 1 & Period 2 & Period 3 & Dynamic & Teaching & Industry & F test \\
\hline Original & 0.25 & 0.3 & 0.45 & 0.835 & 0.763 & 0.908 & $6.58^{* *}$ \\
\hline Case 1 & 0.1 & 0.35 & 0.55 & 0.832 & 0.758 & 0.906 & $7.24^{* *}$ \\
\hline Case 2 & 0.15 & 0.3 & 0.55 & 0.831 & 0.758 & 0.904 & $6.97^{* *}$ \\
\hline Case 3 & 0.15 & 0.35 & 0.50 & 0.834 & 0.760 & 0.908 & $7.08^{* *}$ \\
\hline Case 4 & 0.2 & 0.35 & 0.45 & 0.836 & 0.763 & 0.910 & $6.88^{* *}$ \\
\hline Case 5 & 0.2 & 0.3 & 0.50 & 0.833 & 0.761 & 0.906 & $6.79^{* *}$ \\
\hline F test & & & & $3.1^{*}$ & 0.83 & $4.27^{* *}$ & \\
\hline
\end{tabular}

** denotes the significance level at $5 \%$

(0.79). Among 12 fields of education involved, $75 \%$ of these fields have the average dynamic network efficiency greater than the sample average score at 0.835 . Details of divisional efficiency for individual fields of education in terms of teaching phase and industry responsiveness over three periods involved are shown in Table 9.

\section{Sensitivity analysis}

In this section, a sensitivity analysis is conducted for the overall period-divisional network efficiency and the divisional efficiencies of teaching and industry responsiveness based on stimulation in period weights. The divisional weight is assumed to remain unchanged, carry 0.5 for each as shown in Table 4 because two phases of teaching and industry responsiveness play a crucial role in the VET reforms (NCVER, 2017), thus they should have the equal importance in the Australian VET system. On the other hand, the period weights can be changeable to see whether there is a difference in the estimated efficiency scores if period weights are set by different coefficients. As indicated in Tone and Tsutsui (2014), the rules of setting period weights over multiple periods need to be satisfied. Specifically, the sum of period weights must be equal to one, and the weight for 
the next period must be greater than the previous one. Accordingly, five cases are set, and the overall dynamic network and divisional efficiencies are computed for teaching and industry satisfaction as shown in Table 8 .

As can be observed from Table 8 that the efficiency scores for the whole system, teaching and industry satisfaction are slightly varied across five scenarios considered including the original case presented in the previous section. In a more specific view, the period weights which are similar in period 3 can produce the same result for teaching efficiency scores. For example, cases 1 and 2 have the same weight for Period 3 at 0.55 , and the teaching efficiency scores in these cases are the same at 0.758 . Like the original case and case 4 with the same period weight in Period 3 at 0.45 , then the teaching efficiency score in these scenarios are the same at 0.763 . However, this phenomenon does not occur with industry satisfaction.

In addition, the Hotelling test indicates that changes in efficiency scores among six cases are significantly different at the $5 \%$ level of significance for the industry satisfaction whereas the change in the teaching efficiency is not statistically significant. This implies that the teaching efficiency appears not to respond to period weights whereas the industry satisfaction is sensitive to changes in the period weights. Put it differently, business and industry quickly respond to the performance of VET on all aspects via the industry satisfaction whereas teaching efficiency has not demonstrated further improvement over time. Moreover, the Hotelling test shows that the overall dynamic network efficiency of the VET training is not significant at the $5 \%$ level of significance over six cases. Nevertheless, when testing the difference among the overall network and divisional efficiency scores for individual scenarios, the $\mathrm{F}$ test shows a significant difference for single cases at the $5 \%$ level of significance. Eventually, by looking at the range of teaching efficiency scores (0.758-0.763) and of industry satisfaction (0.906 to 0.910$)$, it can be observed that the choice of the period weights for the original case appears to be appropriate to depict dynamic changes in the VET system over time.

\section{Discussion}

The education quality and industry responsiveness are the important objectives to ameliorate the performance of the Australian VET system. The quality concept is generally multi-faceted and rests on different interpretations such as the quality of teachers, students and systems including the government policy (Harris 2015). While the quality of teaching is difficult to measure in a quantitative term, the teaching efficiency is likely to be an alternative so that the quality of teaching can be embedded in the teaching process and proxied via the completion rate and industry satisfaction. It is argued that the teaching and industry responsiveness divisions are linked together in a unified framework to reflect the overall efficiency of the VET system. Instead investigating the teaching efficiency for TAFE institutions as in Fieger et al (2017), this paper particularly focused on fields of education that would give us an overarching picture without depending on characteristics of individual institutions that would vastly vary according to scales and scopes of academic operations. Our findings show that the VET overall efficiency score is, on average, 0.835 , relatively in line with the overall technical efficiency found in Victorian TAFE institutes at 0.852 (Abbott and Doucouliagos 2002), but being less than the teaching efficiency found in Fieger et al. (2017) at 0.904 using the stochastic frontier 
analysis. We acknowledge that albeit comparing the efficiency results drawn from different studies may be restricted due to using different methods in different socio-economic contexts, it is still useful to have relative comparisons to understand the overall efficiency of the sector of interest. The VET efficiency score accounts for dynamic changes over the surveyed period and in an internally linked structure of teaching and industry satisfaction.

When looking at divisional efficiencies, the efficiency in industry responsiveness is found to be respectable at 0.908 . This result is in line with the result of employment outcome efficiency in Fieger et al (2017) at 0.93 that supports for the comment of Blom and Meyers (2003) that the Australian VET is primarily geared toward meeting the needs of business and industry. This policy has been emphasized that the Australian VET is grounded on the skills and training system industry focused and industry led. Recent studies showed that VET graduates do well in their jobs as compared to those who have not completed a VET qualification (Polidano and Ryan, 2016; Karmel and Fieger 2012; Lee and Coelli 2010a; b; Leigh 2008).

Regarding teaching, our findings revealed that the VET system obtains the teaching efficiency score at 0.763 , meaning that VET needs to improve its performance by $23.7 \%$. This result provides evidence on the lower efficiency of teaching via the enrolment as an input and the completion rate and subject non-pass rate as outputs, being accordant with the recent claims that education quality of VET needs to be lifted up (Braithwaite 2017; Harris 2015). More recently, Toner (2014) revealed that once public VET funding is open to competition, it would go together with persistent decline in the quality of training. This is a serious warning that needs to be concerned by policy makers.

In a more general view, it follows that the teaching efficiency has demonstrated as a key player in the VET system via its high correlation coefficient with the overall efficiency score at the $1 \%$ level of significance even albeit the efficiency in industry satisfaction is much higher. In other words, the teaching efficiency should walk on the same path with the quality of education and the quality of teacher for the aim of increasing workforce engagement, productivity and efficiency in fields of education (Harris 2015; Hodge 2014; Wheelahan and Moodie 2011).

\section{Conclusions}

This study applied the dynamic network DEA model proposed by Tone and Tsutsui (2014) to estimate the efficiency of the Australian VET sector over the period 20082012. This advanced model is used to analyse a network structure of the VET system and capture the dynamic changes of two divisions, teaching and industry responsiveness that are linked together in the VET's operations across multiple periods. Our findings make important contributions to the nascent efficiency literature of the Australian VET sector by exploring in depth the VET training inefficiency throughout connecting various phases in the academic production process and provide more insights about the training dynamic efficiency of the VET sector in a network structure. These results have addressed interests of the Australian VET reform regarding teaching efficiency and industry responsiveness, thus are useful for the government and policy makers' reference to have more adequate information about how the VET reform process can move forward. 
The paper obtained the following important findings. In the first place, the VET overall training efficiency witnesses a change over the surveyed period. The Hotelling test shows that this variation is significant at less than $10 \%$ level of significance $(p=0.08)$. Generally, the Australian VET system could potentially enhance its performance by $16.5 \%$. In a closer look at the network structure, there is a decreasing trend in the VET teaching efficiency. However, this decline is not statistically significant. On average, the VET system needs to improve its teaching efficiency for all 12 fields of education by $23.7 \%$ to obtain the full frontier efficiency. As for the industry satisfaction, the efficiency of this phase varies over the reported period, rose in period 2, then decreased in period 3. This fluctuation appears to fit into the VET reform taskforces established in the late 2013, being the regular year business and industry attended the VET survey. However, to impose this change on the impact of policies is out of our scope of this study by virtue of the nature of complex relationship in the context not being able to be separated.

Secondly, the teaching efficiency of 12 fields of education shows its importance to efficiency of the VET system with correlation coefficient of 0.846 at the $1 \%$ level of significance. By contrast, the correlation coefficient of the industry satisfaction has a positive sign but is insignificantly linked to the overall network efficiency score. Taking a zoomin look at single fields of education, it is found that some fields of education are fully efficient in teaching, but they were inefficient in the industry satisfaction and vice versa. For the entire VET system, no fields of education obtain the fully frontier efficiency. This result is backed up with recently mounting concern of researchers about the education quality of the VET system when the VET reform policy is open to competition in the VET public funding. It goes without saying that further consideration by the government and VET managers would be more essential to improve the VET's performance from teaching phase to meeting the requirements of business and industry.

Finally, a sensitivity analysis was conducted for period weights while keep divisional weights constant and found that changes in the teaching efficiency were insignificant and did fall within the range of 0.758 and 0.763 . On the other hand, the range for the efficiency in industry satisfaction was within 0.906 to 0.910 that was significantly different among different cases. This shows that the industry satisfaction was sensitive to the period weights as the importance of the last period is emphasised. This finding reveals the fact that teaching efficiency has been improved not much over time whereas industry responsiveness to teaching outcomes has been prompt via job performance of the VET graduates, and thus influence the operational efficiency of the entire VET system. This interesting point may appeal the concern of policymakers for adjustment if any for the VET reform process.

This paper has contributed novel insights to policymakers and VET managers about the efficiency of the Australian VET sector, embedded into teaching and industry responsiveness that would be useful for the process of conducting the VET reform not only in Australia but other nations where the VET system plays a curial role in the education system as well. Further research may concern the following points. First, this study has just concentrated two phases of teaching and industry responsiveness without considering other phases that probably may be important for the VET operational process, for example budget government and human resource management. These divisions should be investigated to explore in breadth and depth the VET performance, thus more 
appropriate policies can be proposed to move the VET system forward. Second, specific characteristics of fields of education such as employment demand, teaching and learning facilities, teaching staff and other related factors should be taken account in the performance analysis of the VET training system. Third, the quality variables such as the quality of teaching, learning and management should be included in the analysis to provide more robust assessments, and therefore would give more insightful information for the government on the way conducting a nation's VET reform agenda. Finally, it might be helpful to investigate the influences of exogenous factors on industry satisfaction as an indicator success of the VET sector, thus might affect its overall performance, and use a longer span of data periods, especially after the VET reform agenda to have a larger picture on a dynamic change in the performance of the Australian VET sector.

\section{Appendices}

\section{Data envelopment analysis model}

The data envelopment analysis model was first developed by Charnes, Cooper and Rhodes (1978) to estimate efficiency of decision-making units (DMUs) in terms of assumption that DMUs are operating at the optimal scale. The linear programming equations are expressed as follows:

$$
\begin{aligned}
& \text { Min } \theta-\varepsilon\left(\sum_{i=1}^{m} s_{i}^{-}+\sum_{r=1}^{s} s_{r}^{+}\right) . \\
& \text {subject to } \sum_{j=1}^{n} x_{i j} \lambda_{j}=\theta x_{i j_{o}}-s_{i}^{-} ; i=1, \ldots, m \\
& \quad \sum_{j=1}^{n} y_{r j} \lambda_{j}=y_{r j_{o}}+s_{r}^{+} ; r=1, \ldots, s \\
& \quad 0 \leq \lambda_{j}, s_{i}^{-}, s_{r}^{+} \forall j, i, r ; j=1, \ldots, n
\end{aligned}
$$

where $\varepsilon$ is an arbitrarily small positive number; $\lambda$ is scalar; $m$ is number of inputs; $s$ is the number of inputs and $\mathrm{j}$ is number of DMUs. $s_{i}^{-}$are input slacks to be contracted, $s_{r}^{+}$are output surplus to be expanded. $\theta$ has the value within the range of zero and one. If $\theta=1$, DMU is efficient; if $\theta<1, \mathrm{DMU}$ is inefficient and needs to improve their performance.

It is noted that the assumption of the production function under constant return to scale is not always the case in practice. This is because not all DMUs can operate at the optimal scale due to unexpected influences of environmental factors that are beyond control of DMUs. To tackle this problem, Banker, Charnes and Cooper (1984) extended this model to account for situations of scale effects. Accordingly, the variable return to scale specification is suggested to measure technical efficiency of DMUs without the scale effects. The variable return to scale linear programming problem can be written as follows:

$$
\begin{aligned}
& \operatorname{Min} \theta-\varepsilon\left(\sum_{i_{i}=1}^{m} s_{i}^{-}+\sum_{r=1}^{s} s_{r}^{+}\right) . \\
& \text {subject to } \sum_{j=1}^{n} x_{i j} \lambda_{j}=\theta x_{i j_{o}}-s_{i}^{-} ; i=1, \ldots, m \\
& \qquad \sum_{j=1}^{n} y_{r j} \lambda_{j}=y_{r j_{o}}+s_{r}^{+} ; r=1, \ldots, s
\end{aligned}
$$


Table 9 Divisional efficiencies of teaching and industry responsiveness over the reported periods

\begin{tabular}{|c|c|c|c|c|c|c|c|c|c|}
\hline \multirow[t]{2}{*}{ No } & \multirow[t]{2}{*}{ Field of education } & \multicolumn{4}{|l|}{ Teaching } & \multicolumn{4}{|c|}{ Industry satisfaction } \\
\hline & & Period 1 & Period 2 & Period 3 & Overall & Period 1 & Period 2 & Period 3 & Overall \\
\hline 1 & $\begin{array}{l}\text { Natural and physical sci- } \\
\text { ences }\end{array}$ & 1.00 & 1.00 & 1.00 & 1.00 & 0.88 & 0.83 & 0.79 & 0.82 \\
\hline 2 & Information technology & 0.69 & 0.69 & 0.67 & 0.68 & 1.00 & 1.00 & 0.79 & 0.90 \\
\hline 3 & $\begin{array}{l}\text { Engineering and related } \\
\text { technologies }\end{array}$ & 1.00 & 0.77 & 0.73 & 0.81 & 0.88 & 0.81 & 0.77 & 0.81 \\
\hline 4 & Architecture and building & 1.00 & 1.00 & 0.61 & 0.82 & 0.66 & 1.00 & 0.84 & 0.84 \\
\hline 5 & $\begin{array}{l}\text { Agriculture, environmental } \\
\text { and related studies }\end{array}$ & 0.59 & 0.60 & 0.60 & 0.60 & 1.00 & 1.00 & 1.00 & 1.00 \\
\hline 6 & Health & 0.83 & 0.69 & 0.73 & 0.74 & 0.96 & 1.00 & 0.88 & 0.93 \\
\hline 7 & Education & 1.00 & 1.00 & 1.00 & 1.00 & 0.86 & 1.00 & 1.00 & 0.96 \\
\hline 8 & $\begin{array}{l}\text { Management and com- } \\
\text { merce }\end{array}$ & 0.73 & 0.83 & 0.82 & 0.80 & 0.84 & 0.80 & 0.77 & 0.79 \\
\hline 9 & Society and culture & 0.83 & 0.89 & 0.90 & 0.88 & 1.00 & 1.00 & 1.00 & 1.00 \\
\hline 10 & Creative arts & 0.66 & 0.70 & 0.70 & 0.69 & 1.00 & 1.00 & 0.91 & 0.96 \\
\hline 11 & $\begin{array}{l}\text { Food, hospitality and per- } \\
\text { sonal services }\end{array}$ & 0.64 & 0.67 & 0.59 & 0.63 & 0.92 & 1.00 & 0.75 & 0.87 \\
\hline 12 & Mixed field programs & 0.46 & 0.54 & 0.51 & 0.51 & 1.00 & 1.00 & 1.00 & 1.00 \\
\hline
\end{tabular}

$$
\sum_{j=1}^{n} \lambda_{j}=10 \leq \lambda_{j}, s_{i}^{-}, s_{r}^{+} \forall j, i, r ; j=1, \ldots, n
$$

This model allows one to estimate both pure technical efficiency and scale efficiency. Several software packages are available to solve this problem such as R, DEAP, MAXDEA, etc.

\section{Acknowledgements}

I am grateful for the comments and suggestions made by two anonymous referees. I also appreciate the valuable discussions and ideas made by colleagues and Mr Phan Tran on this paper. Any remaining errors are the responsibility of the author.

\section{Authors' contributions}

C-TTDT is Senior Research Officer at NSW Public Policy Institute, the University of Sydney, NSW, Australia. She is also Honorary Research Fellow at University of Technology, Sydney, Western Sydney University and University of New England, Australia. She has written extensively on tertiary education and local government, especially on operational efficiency, economies of scale and productivity. Recent publications consist of Journal of Further and Higher Education, International Journal of Educational Development, Asia Pacific Journal of Education, Local Government Studies, Public Administration Quarterly, Australian Journal of Public Administration, Public Finance and Management, Applied Economics, Asian Economic Journal, and International Transaction in Operational Journal. The author read and approved the final manuscript.

\section{Funding}

No funding.

\section{Availability of data and materials}

Not applicable.

\section{Declarations}

Competing interests

There is no conflict of interest.

\section{Author details}

${ }^{1}$ NSW Public Policy Institute, The University of Sydney, Sydney, NSW 2006, Australia. ${ }^{2}$ University of Technology Sydney, Western Sydney University and University of New England, NSW, Australia.

Received: 22 November 2020 Accepted: 19 March 2021

Published online: 29 March 2021 
References

Abbott M, Doucouliagos C (2002) A data envelopment analysis of the efficiency of Victorian TAFE institutes. Aust Econ Rev 35(1):55-69

Abbott M, Doucouliagos C (2003) The efficiency of Australian universities: a data envelopment analysis. Econ Educ Rev 22:89-97

Adamson F, Darling-Hammond L (2015) Policy pathways for twenty-first century skills. In: Griffin P, Care E (eds) Assessment and teaching of 21st century skills. Springer, Dordrecht, pp 293-310

ASQA (Australian Skills Quality Authority) (2019) Australia's VET sector. https://www.asqa.gov.au/about/australias-vet-sector. Accessed 15 Mar 2019

Australian Industry Group AlphaBeta (Firm), Australian Technology Network of Universities (ATN), TAFE Directors Australia (TDA) (2020) Skills for tomorrow. Report. Australian Industry Group AlphaBeta (Firm), Australian Technology Network of Universities (ATN), TAFE Directors Australia (TDA), Australia

Avkiran NK (2001) Investigating technical and scale efficiencies of Australian Universities through data envelopment analysis. Socio-Econ Plan Sci 35:57-80

Banker RD, Charnes A, Cooper WW (1984) Some models for estimating technical and scale inefficiencies in data envelopment analysis. ManagSci 30:1078-1092

Berwyn C, Roger H (2018) Recent reforms in vocational education and training. Int J Train Res 16(2):99-102

Bessent AM, Bessent EW, Kennington J, Reagan B (1982) An application of mathematical programming to assess productivity in the Houston independent school district. ManagSci 28:1355-1367

Blom K, Meyers D (2003) Quality indicators in vocational education and training: international perspectives. National Centre for Vocational Education Research, Adelaide

Blumenfeld S, Malik A (2017) Human capital formation under neo-liberalism: the legacy of vocational education training in Australasia and implications for the Asia-Pacific region. Asia Pac Bus Rev 23(2):290-298

Braithwaite V (2017) How do we support quality teaching in Australian VET? Aust TAFE Teacher 51(1):23-25

Braithwaite V (2018) All eyes on quality: Review of the national vocational education and training regulator act 2011 report. The final report review: Department of Education, Skills, and Employment. https://www.dese.gov.au/uncat egorised/resources/all-eyes-quality-review-national-vocational-education-and-training-regulator-act-2011-report Accessed 300ct 2020

Burke G (2018) Changes in funding in Australian vocational education and their effects. NCVER's VOCED. http://hdl.voced. edu.au/10707/461913. Accessed 15 Oct 2019

Carrington R, Coelli TJ, Rao DSP (2005) The performance of Australian universities: conceptual issues and preliminary results. Aust Econ Pap 24:145-163

Carrington R, O'Donnell C, Rao DSP (2018) Australian university productivity growth and public funding revisited. Stud High Educ 43(8):1417-1438

Castano MCN, Cabanda E (2007) Sources of efficiency and productivity growth in the Philippine state universities and colleges: a non-parametric approach. Int Bus Econ Res J 6(6):79-90

Chappell C (2003) Researching vocational education and training: Where to from here? J VocatEduc Train 55(1):21-32

Charnes A, Cooper WW, Rhodes E (1978) Measuring the efficiency of decision—making units. Eur J Oper Res 2:429-444

Chhetri P, Butcher T, Corbitt B (2014) Characterising spatial logistics employment clusters. Int J Phys DistribLogistManag 44(3):221-241

Chhetri P, Gekara V, Manzoni A, Montague A (2018) Productivity benefits of employer-sponsored training: a study of the Australia transport and logistics industry. Educ Train 60(9):1009-1025

Clayton B, Harris R (2018) Recent reforms in vocational education and training. Int J Train Res 16(2):99-102. https://doi. org/10.1080/14480220.2018.1501913

Coelli TJ, Rao DSP, O'Donnell CJ, Battese GE (2005) An introduction to efficiency and productivity analysis, 2nd edn. Springer, New York

Cooper WW, Seiford LM, Zhu J (eds) (2011) Handbook on data envelopment analysis, vol 164. Springer Science and Business Media, Boston

Cordero-Ferrera JM, Pedraja-Chaparro F, Salinas-Jimnez J (2008) Measuring efficiency in education: an analysis of different approaches for incorporating non-discretionary inputs. Appl Econ 40(10):1323-1339

De Witte K, Lopez-Torres L (2017) Efficiency in education A review of literature and a way forward. J Oper Res Soc 68(4):339-359

Emrouznejad A, Thanassoulis E (2005) A mathematical model for dynamic efficiency using data envelopment analysis. Appl Math Comput 160:363-378

Engert $F(1996)$ The reporting of school district efficiency: the adequacy of ratio measures. Public Budg Financial Manag 8:247-271

Farrell MJ (1957) The measurement of productive efficiency. J R Stat Soc Series A 120(3):253-281

Fieger P, Villano RA, Rice J, Cooksey R (2017) Two-dimensional efficiency measurements in vocational education: evidence from Australia. Int J Product Perform Manag 66(2):196-215

Fried HO, Lovell CK, Schmidt SS, Schmidt SS (eds) (2008) The measurement of productive efficiency and productivity growth. Oxford University Press, Oxford

Friedman LS (2002) The microeconomics of public policy analysis. Princeton University Press, Princeton

Harris R (2015) Quality in the Australian VET sector: what has been happening? Int J Train Res 13(1):16-34

Harris R, Clayton B (2010) Impact in vocational education and training research: the case of the Australian VET Research Consortium. Int J Train Res 8(1):6-24

Hodge S (2014) Interpreting competencies in Australian vocational education and training: practices and issues. National Centre for Vocational Education Research, Adelaide

Jacobs R (2001) Alternative methods to examine hospital efficiency: data envelopment analysis and stochastic frontier analysis. Health Care ManagSci 4:103-115

Johnes J (1996) Performance assessment in higher education in Britain. Eur J Oper Res 89(1):18-33 
Johnes J, Yu L (2008) Measuring the research performance of Chinese higher education institutions using data envelopment analysis. China Econ Rev 19:679-696

Joyce S (2019) Strengthening skills: expert review of Australia's Vocational Education and Training System. Report. Commonwealth of Australia: Department of the Prime Minister and Cabinet. Accessed on 30 October 2020 at https:// www.pmc.gov.au/sites/default/files/publications/strengtheningskills-independent-review-australia-vets_1.pdf

Karmel T, Fieger P (2012) The value of completing a VET qualification. National Centre for Vocational Education Research, Adelaide

Köksal G, Nalçaci B (2006) The relative efficiency of departments at a Turkish engineering college: a data envelopment analysis. High Educ 51(2):173-189

Lee BL (2011) Efficiency of research performance of Australian Universities: a reappraisal using a bootstrap truncated regression approach. Econ Anal Policy 41(3):195-203

Lee W-S, Coelli M (2010a) Analysis of private returns to vocational education and training. National Centre for Vocational Education Research, Adelaide

Lee W-S, Coelli M (2010b) The labour market effects of vocational education and training in Australia. Aust Econ Rev 43(4):389-408

Lee BL, Worthington AC (2016) A network DEA quantity and quality-orientated production model: an application to Australian university research services. Omega 60:26-33

Leigh A (2008) Returns to education in Australia. Econ Pap 27(3):233-249

Lindsay AW (1982) Institutional performance in higher education: The efficiency dimension. Rev Educ Res 52(2):175-199 Monfared S, Safi M (2013) Network DEA: an application to analysis of academic performance. J IndEnglnt 9(15):1-10

National Centre for Vocational Education Research (NCVER) (2017). Training product reform: what is the case for change? Accessed at http://hdl.voced.edu.au/10707/447484. Accessed 15 Oct 2019

National Centre for Vocational Education Research (NCVER) (2019) Research and Statistics. https://www.ncver.edu.au/ research-and-statistics. Accessed 15 Mar 2019

NCVER's, Vocational Education and Training Research Database (VOCED, 2014). Annual national report of the Australian vocational education and training system. http://hdl.voced.edu.au/10707/376001. Accessed 30 Oct 2020

O'Donnell CJ, Fallah-Fini S, Triantis K (2017) Measuring and analysing productivity change in a metafrontier framework. J Product Anal 47(2):117-128

Polidano C, Ryan C (2016) Long-term outcomes from Australian vocational education. https://melbourneinstitute.unime Ib.edu.au/publications/working-papers/search/result?paper=2200657. Accessed 15 Mar 2019

Thanassoulis E, Kortelainen M, Johnes G, Johnes J (2011) Costs and efficiency of higher education institutions in England: a DEA analysis. J Oper Res Soc 62:1282-1297

Tone K, Tsutsui M (2009) Network DEA: a slacks-based measure approach. Eur J Oper Res 197:243-252

Tone K, Tsutsui M (2010) Dynamic DEA: a slacks-based measure approach. Omega 38:145-156

Tone K, Tsutsui M (2013) Dynamic DEA with network structure. In: Workshop on DNDEA 2013, pp 1-10

Tone K, Tsutsui M (2014) Dynamic DEA with network structure: a slacks-based measure approach. Omega 42:124-131

Toner P (2014) Contracting out publicly funded vocational education: a transaction cost critique. ELRR 25(2):222-239

Tran C-DTT, Villano RA (2017) An empirical analysis of the academic performance: the case of Vietnamese higher education institutions. J Furth High Educ 41(4):530-544

Tran C-DTT, Villano RA (2018a) Measuring efficiency of Vietnamese public colleges: an application of the DEA-based dynamic network approach. Int Trans Oper Res 25(2):683-703

Tran C-DTT, Villano RA (2018b) Financial efficiencies of Vietnamese public universities: a second-stage dynamic network data envelopment analysis approach. Singapore Econ Rev. https://doi.org/10.1142/S0217590818500133

Weller SA (2017) Accounting for skill shortages? Migration and the Australian labour market. Popul Space Place 23(2):1-14

Wheelahan L, Moodie G (2011) The quality of teaching in VET Final report and recommendations. Department of Education, Employment and Workplace Relations, Australian Government, Canberra

Worthington A (2001) An empirical survey of frontier efficiency measurement techniques in education. Educ Econ 9(3):245-268

Worthington AC, Higgs H (2011) Economies of scale and scope in Australian higher education. High Educ 61(4):387-414

Yudiono H, Budiman FA, Majid MN, Permana KNC (2021) The learning strategy based on scientific approach to strengthen the employability skill of teacher candidates. Int J Instr 14(2):551-570

Zhang LC, Worthington AC (2017) Scale and scope economies of distance education in Australian universities. Stud High Educ 42(9):1785-1799

\section{Publisher's Note}

Springer Nature remains neutral with regard to jurisdictional claims in published maps and institutional affiliations. 